University of South Florida

DIGITAL COMMONS

Digital Commons @ University of

@ UNIVERSITY OF SOUTH FLORIDA

South Florida

\title{
A Global Evaluation of Ocean Bottom Pressure from GRACE, OMCT, and Steric-Corrected Altimetry
}

D. Chambers

University of South Florida, donc@usf.edu

Josh K. Willis

California Institute of Technology

Follow this and additional works at: https://digitalcommons.usf.edu/msc_facpub

Part of the Marine Biology Commons

\section{Scholar Commons Citation}

Chambers, D. and Willis, Josh K., "A Global Evaluation of Ocean Bottom Pressure from GRACE, OMCT, and Steric-Corrected Altimetry" (2010). Marine Science Faculty Publications. 176.

https://digitalcommons.usf.edu/msc_facpub/176

This Article is brought to you for free and open access by the College of Marine Science at Digital Commons @ University of South Florida. It has been accepted for inclusion in Marine Science Faculty Publications by an authorized administrator of Digital Commons @ University of South Florida. For more information, please contact digitalcommons@usf.edu. 


\title{
A Global Evaluation of Ocean Bottom Pressure from GRACE, OMCT, and Steric-Corrected Altimetry
}

\author{
DON P. CHAMBERS \\ College of Marine Science, University of South Florida, St. Petersburg, Florida \\ JOSH K. WILLIS \\ NASA Jet Propulsion Laboratory, California Institute of Technology, Pasadena, California
}

(Manuscript received 2 September 2009, in final form 31 March 2010)

\begin{abstract}
Ocean bottom pressure (OBP) from the Gravity Recovery and Climate Experiment (GRACE) and the Ocean Model for Circulation and Tides (OMCT) are compared globally with OBP computed from altimetry corrected for steric variations from Argo floats from January 2005 to December 2007. Two methods of smoothing the GRACE data are examined. The first uses a standard Gaussian smoother with a radius of $300 \mathrm{~km}$. The second method projects those smoothed maps onto empirical orthogonal functions derived from OMCT in a least squares estimation in order to produce maps that better agree with the physical processes embodied by the model. These new maps agree significantly better with estimates from the steric-corrected altimetry, reducing the variance on average by $30 \%$ over $70 \%$ of the ocean. This is compared to smaller reductions over only $14 \%$ of the ocean using the $300-\mathrm{km}$ Gaussian maps and $56 \%$ of the ocean using OMCT maps. The OMCT maps do not reduce variance as much in the Southern Ocean where OBP variations are largest, whereas the GRACE maps do. Based on this analysis, it is estimated that the local, or point-to-point, uncertainty of new EOF filtered maps of GRACE OBP is 1.3 (one standard deviation).
\end{abstract}

\section{Introduction}

Other than tides, there are three main drivers of ocean bottom pressure (OBP) variability. Locally, the largest arises from changes in wind stress curl and circulation, which force internal mass redistribution. These OBP changes are typically correlated over several thousand kilometers, although even larger-scale exchanges between basins have been simulated in models (Stepanov and Hughes 2006). There are also two smaller components of OBP variability that are correlated over most of the global oceans: the component resulting from water mass entering and leaving the ocean as part of the global water cycle (e.g., Chen et al.1998; Chambers et al. 2004) and the component resulting from atmospheric mass exchange over the ocean and land (e.g., Ponte 1999).

Ocean bottom pressure variations are associated with relatively small signatures in sea level, except in a few

Corresponding author address: Don P. Chambers, College of Marine Science, University of South Florida, 140 7th Ave. S, MSL119, St. Petersburg, FL 33701-5016.

E-mail: dchambers@marine.usf.edu locations, most notably the Southern Ocean (e.g., Ponte 1999). However, even the largest OBP variations are about 10 times smaller than the largest steric variations associated with El Niño or mesoscale eddies. Measuring OBP directly is difficult, which is why there was hope that the Gravity Recovery and Climate Experiment (GRACE) could provide the first global measurements of ocean bottom pressure (Jayne et al. 2003). While GRACE has provided estimates of ocean bottom pressure on monthly intervals since late 2002, the accuracy and hence usefulness of the OBP measurements have been questioned. In fact, early estimates of the error in GRACE estimates of water thickness (equivalent to OBP over the ocean) assumed that the signal was dominated by noise (e.g., Wahr et al. 2004).

However, more rigorous evaluations soon followed. Chambers et al. (2004) demonstrated that the timevariable global mass of the ocean was similar to that predicted by steric-corrected altimetry, at least for the seasonal cycle. Shortly after this, Bingham and Hughes (2006) used empirical orthogonal function (EOF) analysis and found a seasonal mode of OBP variation from GRACE that was similar to that simulated by a model. 
Chambers (2006a) also used EOFs to study the seasonal cycle of local steric sea level (SSL) from data and found that maps of altimetry corrected for OBP from GRACE agreed well with climatological maps of SSL. More recently, after discovery of a correlated error in the gravity coefficients that propagate into north-south "stripes" in the mapped GRACE data (Swenson and Wahr 2006) and new processing by the data centers (Bettadpur 2007), the accuracy of OBP from GRACE has improved. Chambers (2006b) found an improvement from $20 \%$ to $50 \%$ (in terms of variance), depending on the amount of smoothing applied. Ponte et al. (2007) compared the newer data with output from an ocean model globally and found better agreement than had been observed in previous tests.

Recently, two new methods have been tested to further reduce noise in the GRACE data (Böning et al. 2008; Chambers and Willis 2008). Both project noisy GRACE observations onto correlated patterns derived from ocean models to recover maps more consistent with the model dynamics. Böning et al. (2008) computed spatial cross correlations and coherent patterns from nonseasonal OBP output from a model and mapped the GRACE database on weights determined from the correlation. They compared the results with a set of OBP recorders and found increased correlation and lower RMS than for standard Gaussian-filtered GRACE maps. Chambers and Willis (2008) used EOFs from a model to determine coherent patterns and projected the GRACE data onto the patterns using the method of EOF reconstruction (EOFR; e.g., Smith et al. 1996). The basic principle of the EOFR technique is that the spatial maps from a principal component analysis of gridded data are used as multiple basis functions in place of a single covariance function or smoothing functions in order to map sparser data. In essence, the sparse data are fit to a priori EOF spatial patterns in a least squares procedure to estimate the temporal coefficients for each mode. A set of scaling parameters equal to the number of EOF modes used is estimated for each time step. Then, a reconstructed grid is computed by multiplying the estimated scaling parameter for a particular month and the appropriate EOF spatial grid and then summing over all EOF modes. The technique works well, provided that the EOFs accurately represent the patterns of variability at the time of the data to be mapped.

When the EOFR technique is applied to mapped GRACE data, one essentially is projecting the data onto the model EOFs in order to filter out any physical processes that are not present in the numerical model. These processes can include nonrandom noise, systematic errors in the GRACE data, and geodetic signals (like earthquakes and hydrology variations) not related to the ocean state. Chambers and Willis (2008) found that the EOFR of GRACE data reduced noise in the maps significantly, but did not change the longwave variability significantly. The EOFR filtered data were checked against OBP estimated from altimetry corrected for steric variations computed from Argo floats. They found high correlation and low RMS differences, and both datasets observed a large increase in OBP in the subpolar gyre. It is important to note that the model used for the EOF patterns did not simulate the temporal trend very well. This suggested that the model was able to simulate the proper patterns of OBP variability, but not the amplitude and phase. By combining the GRACE and model EOFs, we were able to obtain a more accurate representation of OBP than using either method alone.

Although the method was only tested in the North Pacific, there is no reason to believe that similar results will not hold elsewhere. Here, we will extend the study of Chambers and Willis (2008) globally and validate against a global mapping of altimetry-Argo residuals. In addition to analyzing the EOFR maps, we will compare the original GRACE-only maps as well as the output from the model used to compute the EOF maps. In the next section, we will briefly review the data processing. In section 3, we will compare the GRACE and model OBP data with altimetry-Argo estimates and discuss the results.

\section{Data processing}

In this paper, OBP variation is expressed in terms of the equivalent barotropic sea level change $(\Delta \eta)$, which is related to $\triangle \mathrm{OBP}$ by

$$
\Delta \mathrm{OBP}=\rho g \Delta \eta,
$$

where $\rho$ is an average density of seawater and $g$ is the mean acceleration of gravity (e.g., Ponte 1999). Maps of OBP from the GRACE mission are available at different smoothing radii from late 2002 until early 2009 from the GRACE Tellus Web site (online at http://gracetellus. jpl.nasa.gov/month_mass.html). The details of the processing are discussed in a document on the Web site (Chambers 2007). For this study, we use maps of OBP that have been derived from the Center for Space Research (CSR) at the University of Texas, Austin, although the procedure can be applied to the data from any of the data centers. The data represent the full nontidal monthly ocean bottom pressure variation, including the effects of the mean atmosphere, mean ocean mass, and internal mass redistribution. We use the maps that have been smoothed with a 300-km Gaussian radius weighting function, similar to Chambers and Willis (2008), in order to 
recover the smallest-scale OBP variations that are possible from GRACE.

For the modeled OBP, we use output from the University of Hamburg Ocean Model for Circulation and Tides (OMCT) forced by European Centre for MediumRange Weather Forecasts (ECMWF) winds and pressure at 6-h intervals that is used in GRACE processing to model high-frequency variations in order to reduce aliasing (Thomas 2002; Flechtner 2007). The output from this model is averaged over the same time intervals as a GRACE "month" and is reported by the data processing centers as sets of spherical harmonic gravity coefficients. We have used the CSR monthly averages of the OMCT output and, to be consistent, have mapped them to OBP using the same 300-km Gaussian function as the GRACE data.

OBP can also be estimated from satellite altimetry measurements of total sea level if the steric component is removed (e.g., Vivier et al. 2005). Here, we use in situ temperature and salinity profiles from the Argo array of profiling floats to estimate the SSL correction between the surface and $900 \mathrm{~dB}$. The processing steps are fully described in Chambers and Willis (2008). The sampling of Argo profiles and altimeter data are very different in space and time, however. In a 10-day period, there is typically one profile in a $3^{\circ} \times 3^{\circ}$ area, while there may be hundreds of altimeter measurements (at resolutions approaching $100 \mathrm{~km}$ ) from multiple altimeters over the same area and time interval. To reduce sampling error in our mapping caused by the differing amounts of data, we do not map Argo data and altimeter data separately. Instead, we first interpolate altimetry sea level anomalies (SLAs) to each Argo profile in time and space. The SLAs are from high-resolution gridded maps based on multiple altimeters (Ducet et al. 2000) provided by the Archiving, Validation, and Interpretation of Satellite Oceanographic data (AVISO). We recenter the grids to the same time period as the Argo floats (2004-06), and use bilinear interpolation to map the altimeter-gridded data to the time and location of the Argo profile. At this point, we have a set of total SLA from altimetry and steric sea level anomalies (SSLAs) from Argo floats at the locations of the floats. These are then differenced (SLA - SSLA) to obtain estimates of OBP anomalies at the same location and time. Estimates of OBP produced in this way will include some error resulting from steric variability that occurs below $900 \mathrm{~m}$ as well as nontidal sea level variability that occur on scales shorter than about $150 \mathrm{~km}$ and 7 days, and interpolation error.

The pointwise OBP data are then mapped to monthly $1^{\circ}$ grids using weighted averages, where the weights $\left(W_{S}\right)$ are of the form of a spatial Gaussian function that is comparable to the function used for the GRACE maps,

$$
W_{S}=\exp \left[-\ln (2)\left(\frac{r}{R_{S}}\right)^{2}\right],
$$

where $r$ is the distance $(\mathrm{km})$ from the center of the grid for which the average is desired to the data point and $R_{S}=300 \mathrm{~km}$ to be consistent with the smoothing of the GRACE and OMCT data. Data within a radius of $1000 \mathrm{~km}$ were used to compute the average. However, a grid value was calculated only if the sum of the weights was greater than 4 . This was done to ensure that a reasonable number of points near the grid center were used in the average and that the estimate was not biased toward observations farther away.

There are also several subtle, but important, differences in the three OBP datasets that need to be discussed and corrected before they are compared. The GRACE data theoretically contain the OBP variation from all three components (internal ocean mass redistribution, global ocean mass change, and mean atmospheric pressure change), whereas the OMCT OBP data do not contain the global ocean mass component and the altimetry-Argo OBP maps do not measure the mean atmospheric pressure component (because of the inverted barometer correction applied to the altimetry data). Thus, we need to modify the data to make them consistent. Because we are comparing the GRACE and OMCT data to altimetry Argo data, we have made the GRACE and OMCT data consistent with those of altimetry-Argo. To do this, we first average the monthly OMCT grids globally to determine the time-variable mean OBP from atmospheric pressure, and then remove this from both the OMCT and GRACE data. After doing this, we average the GRACE data to determine the time-variable mean ocean mass component and add this to the OMCT data. No changes are made to the altimetry-Argo data in order to keep them completely independent of the other two datasets.

One also has to be careful with the data near land for several reasons. Because of the smoothing used and the relatively larger hydrology fluctuations, land water storage variations can leak into the GRACE data in coastal regions (e.g., Chambers 2006a). Although we have attempted to reduce this with an estimate of hydrology variability (Chambers 2007), there will still be leakage error. Because Argo floats operate in deep ocean waters, any grid points in the altimetry-Argo maps for coastal waters are extrapolated from deep-water data. Finally, OMCT simulates the largest OBP variability in certain shallow-water areas, like the Indonesian Sea and South China Sea. These signals tend to dominate the lowest EOF modes unless they are edited out (e.g., Chambers and Willis 2008). Therefore, before computing EOFs or 


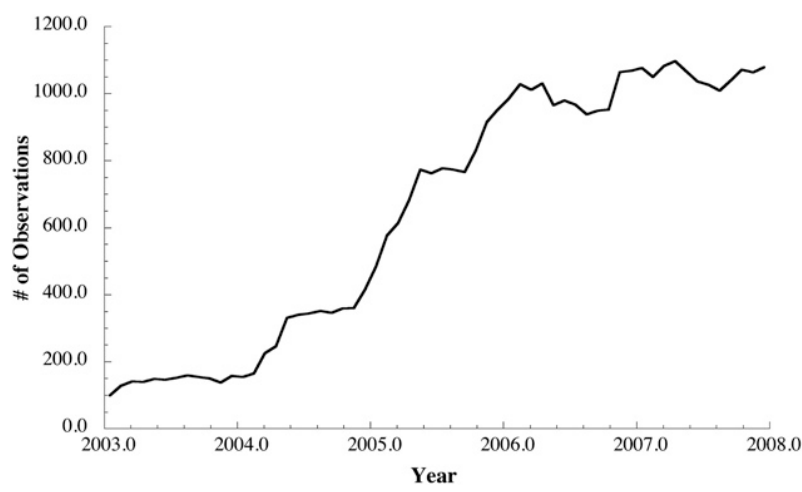

FIG. 1. Monthly number of Argo observations in the Southern Ocean (south of $40^{\circ} \mathrm{S}$ ).

comparing maps, all data within $500 \mathrm{~km}$ of continents and major islands are masked.

We will use the EOF reconstruction technique described by Smith et al. (1996), which was used previously to filter GRACE data in the North Pacific (Chambers and Willis 2008). Global monthly GRACE OBP grids are used as observations $[O(x, t)]$ and the EOF modes from the monthly OMCT OBP maps are used as the spatial basis functions, $\alpha_{k}(x)$. Associated time variations $\left[W_{k}(t)\right]$ are estimated for each month $t$ and mode $k$ to minimize

$$
\varepsilon=O(x, t)-\left[\sum_{k=1}^{N} W_{k}(t) \alpha_{k}(x)\right],
$$

using linear least squares estimation. For each month, $N$ parameters will be estimated. Reconstructed grids of OBP $R(x, t)$ are then computed based on the estimated parameters (designated by the angle brackets)

$$
R(x, t)=\sum_{k=1}^{N}\left\langle W_{k}(t)\right\rangle \alpha_{k}(x) .
$$

EOFs were estimated from OMCT for the time span of August 2002-December 2008 and used in the estimation of $\left\langle W_{k}(t)\right\rangle$ for monthly GRACE data over the same time period. Although the first four modes explained almost $90 \%$ of the variance in the North Pacific, we found that 10 modes were necessary in the global calculation to explain the same level of variance. We therefore use 10 modes to reconstruct GRACE maps used in this analysis.

\section{Discussion of results}

We have computed altimetry-Argo OBP maps from January 2003 until December 2007, but the grids are not full. Part of this is due to fact that Argo floats were still
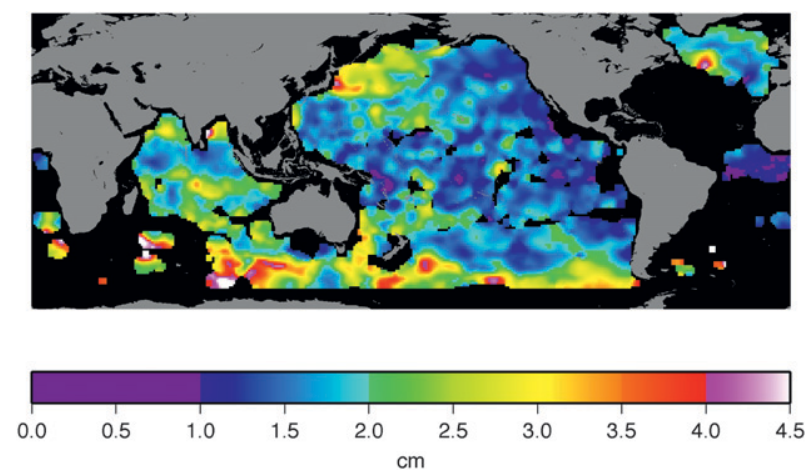

FIG. 2. Standard deviation of OBP (in centimeters of water) estimated from mapped altimetry-Argo data. The standard deviation was computed for monthly grids from January 2005 until December 2007. Regions with fewer than four Argo and altimetry observations within $300 \mathrm{~km}$ are black.

being deployed in the Southern Ocean between 2003 and early 2005 (Fig. 1). There are also gaps in the Atlantic resulting from the fact that many of the early floats in the Atlantic were found to have large errors in reported pressures (Willis et al. 2009) and have been removed from the analysis. After testing various time periods between January 2003 and December 2007, we found that January 2005-December 2007 allowed for approximately $75 \%$ or higher coverage in time over most portions of the ocean, including most of the Southern Ocean. The main exception is in the Atlantic Ocean south of $40^{\circ} \mathrm{N}$ except for a few isolated areas (Fig. 2). However, because the models predict low OBP variability in most of the Atlantic, we deemed this sufficient coverage for our comparisons.

The standard deviation of the altimetry-Argo OBP is consistent with what one would expect from model simulations (Fig. 2). The largest variations are in the Southern Ocean and the subpolar North Pacific, with smaller variability near the equator. To test the GRACE and OMCT OBP maps, they are differenced from the altimeter-Argo maps, and the standard deviation of the residuals in each $1^{\circ}$ grid cell is calculated (Fig. 3). The standard deviation was calculated in a grid cell only if at least $50 \%$ of the months had a value. A decrease in standard deviation indicates a good match between the two data, whereas an increase indicates a poor match.

The standard deviation of the residuals made with the 300-km smoothed GRACE data (Fig. 3a) increased over most of the ocean, except in the regions of the highest variability in the Southern Ocean (e.g., the South Indian Ocean), where there was a decrease. This corroborates other studies (e.g., Ponte et al. 2007) that found that the signal-to-noise ratio of these grids is poor except in regions of the highest variability. Although the residuals with OMCT have lower RMS over most of the ocean 
a)

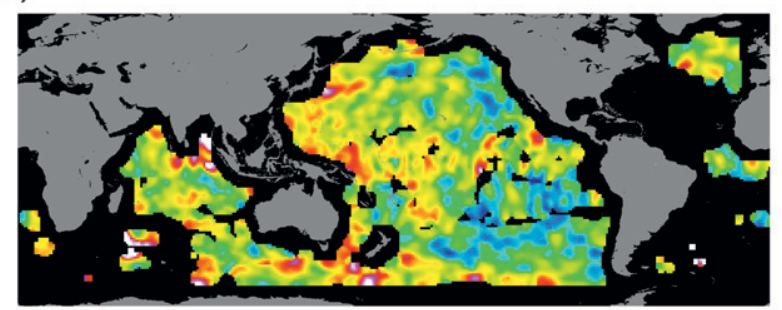

b)

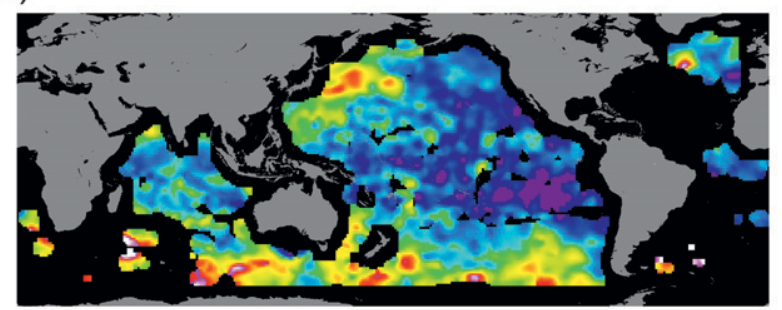

c)
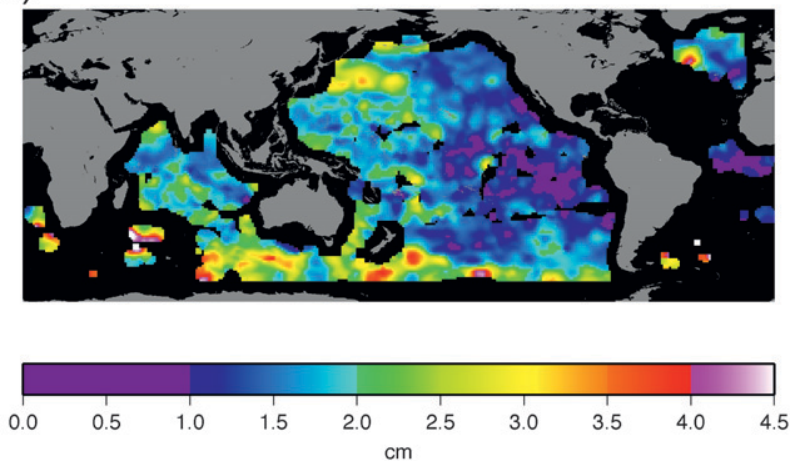

FIG. 3. Standard deviation of residuals of (a) altimetry-ArgoGRACE 300-km grids, (b) altimetry-Argo-OMCT, and (c) altimetry-Argo-GRACE_EOFR.

between $\pm 45^{\circ}$ latitude (Fig. $3 \mathrm{~b}$ ), this cannot be attributed to the model alone because the original grids have very little variability here. It is likely due to the ocean mass correction, which has a standard deviation of nearly $1 \mathrm{~cm}$ globally. In fact, the standard deviation increases in several regions of high OBP variability in the Southern Ocean west of South America and in the North Pacific, and there is no change in the South Indian Ocean. This suggests that either the model variability is not properly simulating the timing of the OBP variability there, or there is a deficiency in the mapping of the altimetry-Argo data in these regions.

However, the fact that the standard deviation of the GRACE EOFR residuals is lower in all of these regions a)

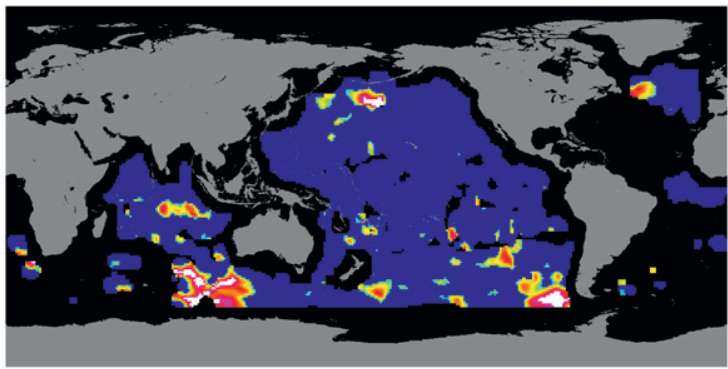

b)

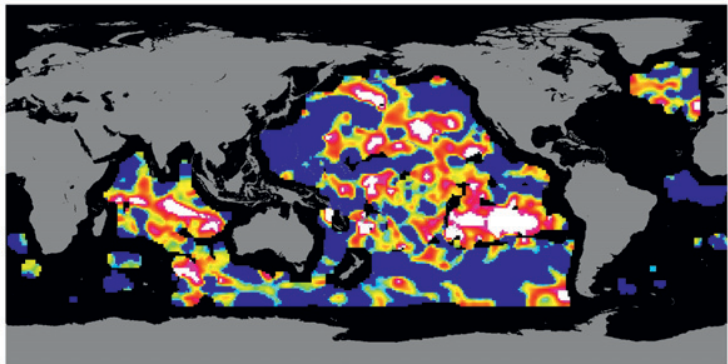

c)
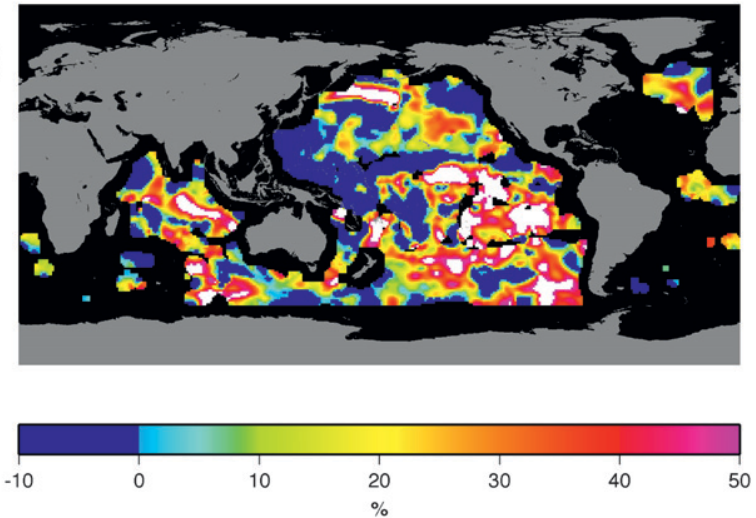

FIG. 4. Percent of variance reduced using (a) GRACE $300-\mathrm{km}$ grids, (b) OMCT, and (c) GRACE EOFR maps, relative to the altimetry-Argo variance (Fig. 2).

(Fig. 3c) suggests that the problem lies in OMCT. It is important to reiterate that although the OMCT EOFs were used in the EOF reconstruction, the phase and amplitude of the variability are determined solely by GRACE. The EOFR procedure also significantly reduces the noise in the original GRACE grids, which is reflected in the decrease in standard deviation over most of the ocean, compared to an increase with the original GRACE-only grids.

The changes are even more apparent when we plot the percent of variance reduction (Fig. 4), computed by

$$
\% \text { Variance Reduction }=100 \frac{\operatorname{Var}\left(\mathrm{OBP}_{\text {Alt-Argo }}\right)-\operatorname{Var}\left(\mathrm{OBP}_{\text {GRACE,OMCT }}-\mathrm{OBP}_{\text {Alt-Argo }}\right)}{\operatorname{Var}\left(\mathrm{OBP}_{\text {Alt-Argo }}\right)} .
$$


a)

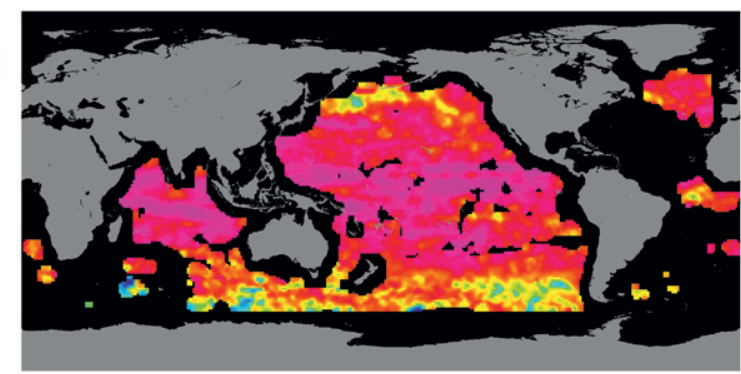

b)

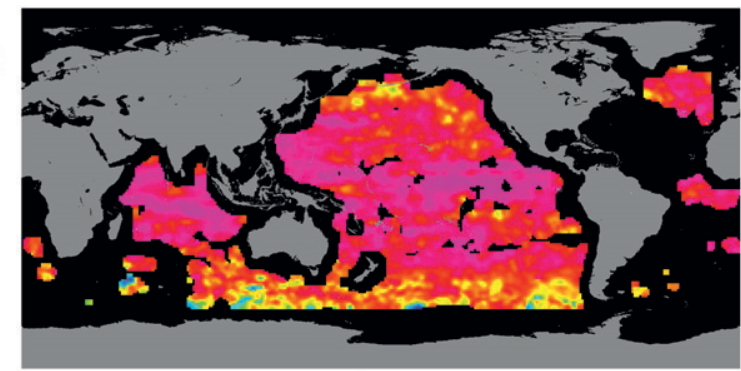

0.0

0.2

0.4

0.6

0.8

FIG. 5. Correlation between altimetry-Argo OBP maps and (a) OMCT and (b) GRACE EOFR maps. Correlations above 0.4 are considered significant at the $1 \%$ level.

Here, we have computed the reduction so that positive values mean that the variance of the altimetry-Argo OBP has decreased when the GRACE or OMCT OBP has been subtracted, while a negative value means the variance has increased. The GRACE-only grids reduce the variance anywhere from $25 \%$ to $50 \%$ only in regions of high OBP variability (Fig. 4a); in most other regions the variance increases by very large amounts. Although the color bar only goes to $-10 \%$, values are as large as $-900 \%$. OMCT grids (with the global mass correction) reduce the variance by a similar amount (Fig. 4b), albeit mainly in regions of low OBP variability. The GRACE EOFR grids (Fig. 4c), however, reduce the variance by $25 \%-50 \%$ in regions of both low and high OBP variability. In all, the GRACE EOFR data reduce variance by on average $28 \%$ for $70 \%$ of the ocean, whereas OMCT data reduce the variance by a similar amount for only $56 \%$ of the ocean. The overall variance of the altimetryArgo maps is $6.2 \mathrm{~cm}^{2}$. Compare this with $4.5 \mathrm{~cm}^{2}$ for residuals from differencing with OMCT and $3.9 \mathrm{~cm}^{2}$ for GRACE EOFR residuals. While the OMCT data do decrease the variance significantly (by $27 \%$ ), the variance reduction using GRACE EOFR maps is even larger (37\%).

The correlation statistics also indicate that the GRACE EOFR maps agree better with altimetry-Argo than the OMCT maps (Fig. 5). The correlation is as low

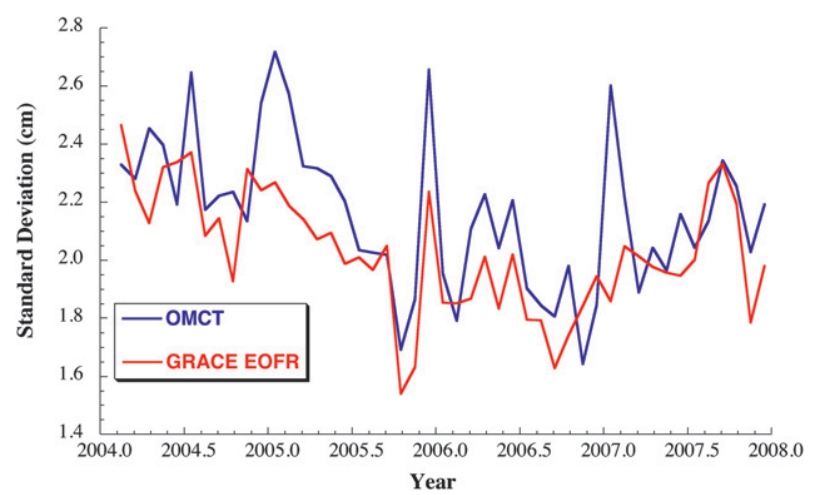

FIG. 6. Monthly standard deviation of OBP residuals between altimetry-Argo maps and OMCT (blue) and GRACE EOFR (red).

as 0.4 to 0.5 in the Southern Ocean and North Pacific with OMCT, but is typically more than 0.6 with the GRACE EOFR maps. Correlations above 0.4 are considered significant at the $1 \%$ level. The high correlation throughout much of the ocean is due to the large seasonal variation in global mean ocean mass, which is observed in both GRACE and steric-corrected altimetry (e.g., Chambers et al. 2004). Correlations are lower only in regions where local OBP variations are much larger than the global mean ocean mass. The correlations in these regions are higher when the GRACE EOFR maps are used, though. On average, the altimeter-ArgoGRACE EOFR residuals have $22 \%$ smaller variance than altimeter-Argo-OMCT residuals south of $35^{\circ} \mathrm{S}$, and $6 \%$ smaller variance north of $35^{\circ} \mathrm{N}$, with insignificant differences between $35^{\circ} \mathrm{S}$ and $35^{\circ} \mathrm{N}$. Likewise, the correlation between the altimeter-Argo grids and GRACE EOFR maps is $7 \%$ higher than with the OMCT maps south of $35^{\circ} \mathrm{S}$ and $2 \%$ higher north of $35^{\circ} \mathrm{N}$, with only minor differences between $35^{\circ} \mathrm{S}$ and $35^{\circ} \mathrm{N}$. Finally, monthly standard deviation of the global residuals (including the maps from 2004 that were not used in the previous statistics) indicates that the GRACE EOFR maps consistently agree better with the altimetry-Argo data than do the OMCT grids (Fig. 6). There are only a few months when OMCT grids agree better with the altimetry-Argo grids than the GRACE EOFR data do. However, there are many instances where the GRACE EOFR maps give significantly smaller residuals for periods of up to a year (e.g., 2005). The variance difference is sometimes more than $80 \%$. Both the OMCT and GRACE EOFR residuals have, on average, lower standard deviations after the middle of 2005. This is most likely due to reduced mapping error in the altimetryArgo grids resulting from increasing observations in the Southern Ocean after the middle of 2005. If we consider the data after June 2005 to have the lowest sampling 
error, we can infer a maximum uncertainty in the GRACE EOFR maps of $1.9 \mathrm{~cm}$ (one standard deviation), based on the standard deviation of the residuals. This, however, assumes that the altimetry-Argo maps have no error, which is, of course, overly optimistic. We know from tide gauge comparisons with altimetry that the altimeter data alone at this resolution have uncertainties at the $1-2-\mathrm{cm}$ RMS level (Cheney et al. 1994), and deep steric signals, below $900 \mathrm{~dB}$, may cause similar errors in some regions (Roemmich et al. 2007). If we consider the combined effects of error in the GRACE and altimetry-Argo maps, then the standard of deviation of the residuals will be

$$
\begin{aligned}
\sigma_{\text {residuals }}^{2}= & \sigma_{\text {GRACE error }}^{2}+\sigma_{\text {alt-Argo error }}^{2} \\
& +2 \sigma_{\text {GRACE error }} \sigma_{\text {alt-Argo error }}
\end{aligned}
$$

Because there is no reason to believe that the error in the GRACE and altimetry-Argo maps are correlated, then the third term in (6) will be approximately zero, so that

$$
\sigma_{\text {residuals }}^{2} \approx \sigma_{\text {GRACE error }}^{2}+\sigma_{\text {alt-Argo error }}^{2}
$$

If we knew the uncertainty of the altimeter-Argo maps, we could calculate a better estimate of the uncertainty in the GRACE maps. Because we do not know this, we will assume they are of the same magnitude so that

$$
\sigma_{\text {residuals }}^{2} \approx 2 \sigma_{\text {GRACE error }}^{2}
$$

Substituting in the observed value of the residual standard deviation $(1.9 \mathrm{~cm})$, we can solve for a lower bound of the uncertainty of $1.3 \mathrm{~cm}$ (one standard deviation).

\section{Conclusions and future work}

We have tested a method of further reducing noise in GRACE OBP data by projecting the data onto EOFs from an ocean model. The filtered maps were compared to independent estimates of OBP from steric-corrected altimetry from January 2005 until December 2007. The steric correction was derived from nearly coincident Argo floats. We also compared OBP from the ocean model (OMCT) that was used in the GRACE processing as an initial guess of the state estimation process. There has been a notion among many investigators that OBP variability observed by GRACE is mainly due to restoring the background (OMCT) model used in the processing. However, the results of this investigation clearly show that the GRACE data actually correct deficiencies in the model. Even without the EOF reconstruction filtering, the 300-km smoothed GRACE grids agree better with the altimetry-Argo data than the model in regions of high
OBP variability. However, by combining the patterns of OBP variability from the model with GRACE data in the EOF reconstruction, we are able to significantly reduce the noise in the GRACE data and improve the maps of OBP.

There are two important implications for this study. The first involves using combinations of altimetry and GRACE to predict steric sea level (and heat storage) as proposed before launch by Jayne et al. (2003), and then first tested by Chambers (2006a), with only minor success. Although the Argo array is now nearly complete, there are still significant gaps before 2005, and there continue to be gaps in the Atlantic. Using altimeter data that are corrected for OBP from EOFR-filtered GRACE data is likely now a better initial guess and gap filler in the optimal interpolation than using climatological values. In addition, the altimeter-GRACE maps are likely a better longwave representation of the steric sea level and so will provide an improved reference.

The second implication is more subtle. The GRACE data contain gravitational signals related to ocean bottom pressure variability, but also geodetic signals related to gravitational changes on land. An example of this is the melting of ice on a glacier or ice sheet near the ocean (e.g., Tamisiea et al. 2001). The gravitational pull of the grounded ice over time attracts water, making it higher than the mean geoid in the near field. If the ice melts, the attraction is reduced and sea level will drop near the glacier (e.g., Tamisiea et al. 2001; Bamber et al. 2009). This should be reflected in both the altimeter and GRACE measurements, but it is not included in the ocean model physics. By projecting the GRACE data onto the model EOFs, the resulting grids have variations only where the model predicts them. This may help to isolate the oceanographic signal from the geodetic one in the GRACE data.

The regularly smoothed GRACE grids (and altimetryArgo grids) will contain both the oceanographic and geodetic signals. Careful analysis of the residuals between altimetry-Argo and GRACE EOFR maps may reveal the global geodetic fingerprints of sea level change that are caused by present-day melting of grounded ice and land surface mass change. Although predicted (e.g., Tamisiea et al. 2001; Bamber et al. 2009), observational evidence of these global fingerprints has yet to be presented. The only evidence comes from analysis with a limited number of long tide gauge records, most of which are near the ice sheets (e.g., Tamisiea et al. 2001). Discovery of the global fingerprints would have important implications for geophysics and our understanding of the patterns of past and future sea level rise. The patterns predicted by present theoretical studies are all based on models that do not reflect the exact density distribution 
of the earth (e.g., Bamber et al. 2009), and the real selfgravitational pattern may differ significantly.

Acknowledgments. We thank V. Zlotnicki and M. Watkins for comments on an earlier draft of this paper. The GRACE data were computed with support by the NASA Earth Science REASoN and "Making Earth System Data Records for Use in Research Environments" (MEASURES) Programs (available at http:// grace.jpl.nasa.gov). The altimeter products were produced by Ssalto/Duacs and distributed by AVISO with support from CNES and are available online (http:// www.aviso.oceanobs.com/en/data). The float data were collected and made freely available by the International Argo Project (a pilot program of the Global Ocean Observing System) and contributing national programs (available at http://www.argo.net). Support for the research was provided by the aforementioned REASoN and MEASURES programs through a subcontract with the Jet Propulsion Laboratory and Grant NNX08AF01G from the NASA GRACE Science Team.

\section{REFERENCES}

Bamber, J. L., R. E. M. Riva, B. L. A. Vermeersen, and A. M. LeBrocq, 2009: Reassessment of the potential sea-level rise from a collapse of the West Antarctic Ice Sheet. Science, 324, 901, doi:10.1126/science.1169335.

Bettadpur, S., 2007: Level-2 gravity field product user handbook. University of Texas at Austin, GRACE 327-742, CSR Publ. GR-03-03, 18 pp.

Bingham, R. J., and C. W. Hughes, 2006: Observing seasonal bottom pressure variability in the North Pacific with GRACE. Geophys. Res. Lett., 33, L08607, doi:10.1029/2005GL025489.

Böning, C., R. Timmermann, A. Macrander, and J. Schröter, 2008: A pattern-filtering method for the determination of ocean bottom pressure anomalies from GRACE solutions. Geophys. Res. Lett., 35, L18611, doi:10.1029/2008GL034974.

Chambers, D. P., 2006a: Observing seasonal steric sea level variations with GRACE and satellite altimetry. J. Geophys. Res., 111, C03010, doi:10.1029/2005JC002914.

_ 2006b: Evaluation of new GRACE time-variable gravity data over the ocean. Geophys. Res. Lett., 33, L17603, doi:10.1029/ 2006 GL027296.

_- 2007: Converting release-04 gravity coefficients into maps of equivalent water thickness. Jet Propulsion Laboratory Rep., 9 pp.

_- and J. K. Willis, 2008: Analysis of large-scale ocean bottom pressure variability in the North Pacific. J. Geophys. Res., 113, C11003, doi:10.1029/2008JC004930.
— J. Wahr, and R. S. Nerem, 2004: Preliminary observations of global ocean mass variations with GRACE. Geophys. Res. Lett., 31, L13310, doi:10.1029/2004GL020461.

Chen, J. L., C. R. Wilson, D. P. Chambers, R. S. Nerem, and B. D. Tapley, 1998: Seasonal global water mass balance and mean sea level variations. Geophys. Res. Lett., 25, 35553558 .

Cheney, R., L. Miller, R. Agreen, N. Doyle, and J. Lillibridge, 1994: TOPEX/POSEIDON: The 2-cm solution. J. Geophys. Res., 99, 24 555-24 563.

Ducet, N., P. Y. Le Traon, and G. Reverdin, 2000: Global highresolution mapping of ocean circulation from TOPEX/Poseidon and ERS-1 and -2. J. Geophys. Res., 105, 19 477-19 498.

Flechtner, F., 2007: AOD1B product description document for product releases 01 to 04 . University of Texas at Austin, GRACE 327-750, CSR Publ. GR-GFZ-AOD-0001 Rev. 3.1, $43 \mathrm{pp}$.

Jayne, S. R., J. M. Wahr, and F. O. Bryan, 2003: Observing ocean heat content using satellite gravity and altimetry. J. Geophys. Res., 108, 3031, doi:10.1029/2002JC001619.

Ponte, R. M., 1999: A preliminary model study of the large-scale seasonal cycle in bottom pressure over the global ocean. J. Geophys. Res., 104, 1289-1300.

— K. J. Quinn, C. Wunsch, and P. Heimbach, 2007: A comparison of model and GRACE estimates of the large-scale seasonal cycle in ocean bottom pressure. Geophys. Res. Lett., 34, L09603, doi:10.1029/2006GL029599.

Roemmich, D., J. Gilson, R. Davis, P. Sutton, S. Wijffels, and S. Riser, 2007: Decadal spinup of the South Pacific subtropical gyre. J. Phys. Oceanogr., 37, 162-173.

Smith, T. M., R. W. Reynolds, R. E. Livezey, and D. C. Stokes, 1996: Reconstruction of historical sea surface temperatures using empirical orthogonal functions. J. Climate, 9, 1403-1420.

Stepanov, V. N., and C. W. Hughes, 2006: Propagation of signals in basin-scale ocean bottom pressure from a barotropic model. J. Geophys. Res., 111, C12002, doi:10.1029/2005JC003450.

Swenson, S., and J. Wahr, 2006: Post-processing removal of correlated errors in GRACE data. Geophys. Res. Lett., 33, L08402, doi:10.1029/2005GL025285.

Tamisiea, M., J. X. Mitrovica, G. A. Milne, and J. L. Davis, 2001: Global geoid and sea-level changes due to present-day ice mass fluctuations. J. Geophys. Res., 106, 30 849-30 863.

Thomas, M., 2002: Ocean induced variations of Earth's rotationResults from a simultaneous model of global ocean circulation and tides. Ph.D. thesis, University of Hamburg, 129 pp.

Vivier, F., K. A. Kelly, and M. Harismendy, 2005: Causes of largescale sea level variations in the Southern Ocean: Analyses of sea level and a barotropic model. J. Geophys. Res., 110, C09014, doi:10.1029/2004JC002773.

Wahr, J., S. Swenson, V. Zlotnicki, and I. Velicogna, 2004: Timevariable gravity from GRACE: First results. Geophys. Res. Lett., 31, L11501, doi:10.1029/2004GL019779.

Willis, J. K., J. M. Lyman, G. C. Johnson, and J. Gilson, 2009: In situ data biases and recent ocean heat content variability. J. Atmos. Oceanic Technol., 26, 846-852. 